\title{
Hantavirus Enfeksiyonlarında Prognostik Faktörler
}

\author{
Prognostic Factors in Hantavirus Infections
}

\author{
Selçuk KAYA \\ Karadeniz Teknik Üniversitesi Tıp Fakültesi, Enfeksiyon Hastalıkları ve Klinik Mikrobiyoloji Anabilim Dalı, Trabzon. \\ Karadeniz Technical University Faculty of Medicine, Department of Infectious Diseases and Clinical Microbiology, Trabzon, \\ Turkey.
}

Geliş Tarihi (Received): 01.08.2013• Kabul Ediliş Tarihi (Accepted): 28.08.2013

\section{ÖZET}

Bunyaviridae ailesinin Hantavirus cinsi içinde yer alan hantaviruslar, insanda renal sendromla seyreden kanamalı ateş (RSKA) ve hantavirus pulmoner sendromu (HPS) adıyla bilinen iki farklı tipte klinik tabloya neden olmaktadırlar. Bu enfeksiyonların mortalitesi \%40’lara kadar yükselebilmektedir. Mortalite üzerine etkili olan faktörlerin başında, virülansları farklı olan hantavirus alt tipleri (Sin Nobre, Hantaan, Seoul, Puumala, Dobrava vb.) gelmektedir. Bunun dışında yaş, cinsiyet, hümoral immün yanıt, genetik faktörler, hastanın klinik ve laboratuvar bulguları, transfüzyon, mekanik ventilasyon gereksinimi, hastalara uygulanan antiviral tedavi ve immünoterapi gibi daha birçok faktör de prognostik açıdan önem arz etmektedir. Artan yaş mortalite üzerine olumsuz etki etmektedir. Hastalık sıklıkla erkek cinsiyette görülmesine rağmen, mortalite oranlarının kadınlarda daha yüksek olduğu dikkati çekmektedir. Gelişen nötralizan antikor yanıtının yeterliliği, virusun yayılımının sınırlandırılmasında ve enfekte olan hücre sayısı, dolayısıyla da sitotoksik T lenfosit aracılı hücre hasarının azaltılmasında önem taşımaktadır. HLA-B8, -DR3, -DQ2 alellerine sahip bireylerde hemodiyaliz ihtiyacının daha fazla ve prognozun daha kötü olduğu; HLA-B27 aleline sahip olanlarda ise hastalığın daha hafif seyrettiği bildirilmektedir. Klinik olarak; çoğul, santral sinir sistemi kanaması olan, sepsis tablosunda olan, disemine intravasküler koagülasyon (DIC) ve sekonder enfeksiyon gelişen olgularda mortalite riski artmaktadır. HPS'nda erişkin solunum distres sendromu (ARDS) gelişimi, mekanik ventilasyon desteği gerekliliği, dispne ve hemokonsantrasyon olması, ölümle ilişkili en önemli prognostik faktörlerdir. Trombositopeninin şiddeti ve hastada transfüzyon gerekliliği de mortalite ile ilişkilidir. Hastanın ilk başvurusunda, serum beyaz küre sayısı, kan üre nitrojeni (BUN), kreatinin fosfokinaz (CPK), C-reaktif protein (CRP), protrombin zamanı (PT), aktive parsiyel tromboplastin zamanı (aPTT), D-dimer ve INR (International normalized ratio) değerlerinin yüksek olması, prognostik açıdan önemli faktörler olup, mortalite riskini artırmaktadırlar. Hemodiyaliz desteği, özellikle Hantaan ve Dobrava virus ile enfekte olgularda çok önemlidir. Solunum desteği ve mekanik ventilasyon uygulaması da HPS olgularında yaşam kurtarıcı olabilmektedir. HPS'de ayrıca ekstrakorporeal membran oksijenizasyonu desteğinin, hastanın Tel (Phone): +90 462377 5632, E-posta (E-mail): eselkaya@yahoo.com 
sağkalımına olumlu katkı sağladığı da gösterilmiştir. Ribavirinin RSKA'nın şiddetini, hemodiyaliz ihtiyacını ve mortaliteyi azalttığı bildirilmekle birlikte, HPS için etkinliği gösterilmemiştir. Sonuç olarak, bu hastalarda prognostik faktörlerin iyi değerlendirilmesi, sağlık uygulamalarında hekimlere hastalığın seyri ve gerekli tedavi yaklaşımının sağlanması açııından öngörü kazandıracaktır.

Anahtar sözcükler: Hantavirus; enfeksiyon; prognoz; mortalite.

\begin{abstract}
The hantaviruses classified in Hantavirus genus of Bunyaviridae family, may cause two different types of clinical conditions, namely hemorrhagic fever with renal syndrome (HFRS) and hantavirus pulmonary syndrome (HPS). Mortality may reach up to $40 \%$ in these infections. Hantavirus subtypes (Sin Nombre, Hantaan, Seoul, Puumala, Dobrava, etc) with different virulences represent one of the most significant factors affecting the mortality. Additionally, many other factors including age, gender, humoral immune response, genetic factors, patient's clinical and laboratory findings, transfusion, mechanical ventilation requirement, antiviral treatment and immunotherapy administered to the patient are prognostically important. Increasing age had an unfavorable effect on mortality. While the disease is commonly observed in the male gender, mortality rate is higher in the female gender. The higher the emergent neutralizing antibody response, the virus spread, the number of the infected cells and the cytotoxic $T$ lymphocyte-mediated injury will be lower. The requirement for dialysis is reported to be higher with a poorer prognosis in individuals with HLA-B8, -DR3, -DQ2 alleles, and those with HLA-B27 allele usually experience a milder clinical course. Clinically, the risk of mortality increases in patients with multiple, central nervous system hemorrhage, sepsis, disseminated intravascular coagulation (DIC) and secondary infection. The presence of adult respiratory distress syndrome (ARDS), the requirement for mechanical ventilation, the presence of dyspnea and hemoconcentration in HPS are reported to be the most important prognostic factors associated with death. The correlation of severity and the transfusion requirement with mortality was demonstrated. High serum levels of white blood cells, blood urea nitrogen (BUN), creatinine phophokinase (CPK), C-reactive protein (CRP), prothrombin time (PT), activated partial thromboplastin time (aPTT), D-dimer and INR (International normalized ratio) are prognostic factors that increase the mortality risk. Hemodialysis support is particularly important in cases infected with Hantaan and Dobrava viruses. Respiratory support and mechanical ventilation can be life-saving in HPS cases. Extracorporeal membrane oxygenation support has been demonstrated to have a favorable contribution to the patient survival in HPS. While there are some human and animal trials showing that ribavirin reduces the severity of HFRS, hemodialysis requirement and mortality, its efficacy for HPS has not yet been demonstrated. As a result, a proper evaluation of the prognostic factors will provide physicians a perspective with respect to the disease course and the necessary treatment approach.
\end{abstract}

Key words: Hantavirus; infection; prognosis; mortality.

\title{
Giriş
}

Hantaviruslar, Bunyaviridae ailesinin Hantavirus cinsinde yer alan ve kemiriciler aracıIığıyla insanlara bulaşan zarflı RNA viruslarıdır. Günümüzde hantavirusların 30'dan fazla türü saptanmış olup, bunlardan en az 20 kadarının insanda hastalık yaptığı bilinmekte$\operatorname{dir}^{1,2}$. Kemiricilerde sıklıkla asemptomatik, kronik taşıyıcılık şeklinde seyreden enfeksiyon, insanlarda renal sendromla seyreden kanamalı ateş (RSKA) ve hantavirus pulmoner sendrom (HPS) adıyla bilinen iki farklı tipte klinik tabloyla karşımıza çıkmaktadır ${ }^{3,4}$. HPS ilk olarak Kuzey Amerika'da Sin Nombre eyaletinde görüldüğü için, etkeni olan virus aynı 
adla (Sin Nombre virus; SNV) anılmıştır. Yaygın pulmoner ödem, pulmoner fonksiyonlarda bozulma ve kardiyovasküler yetmezlik tablosuna yol açması nedeniyle mortalitesi oldukça yüksektir. Daha sonraları Andes, Negra, Laguna, New York gibi HPS nedeni olan farklı virus alt tipleri de tespit edilmiştir ${ }^{2,4,5}$. RSKA olgularının ise büyük çoğunluğu Güneydoğu Asya ve Rusya'da görülmekte olup, virusun coğrafi dağılımlarına göre farklılık gösteren birçok alt tipi mevcuttur. Bunlardan Asya'da Hantaan (HTNV) ve Seoul virus (SEOV), Avrupa'da ise Puumala (PUUV) ve Dobrava virus (DOBV) en yaygın olanlarıdır ${ }^{2,4}$.

Ülkemizde hantavirusların varlığını gösteren ilk çalışma, 2004 yılında kuzeydoğu ve batı bölgelerimizde kemiricilerde yapılan bir araştırma olup, kemiricilerde hantavirus PUUV alt tipinin varlığı tespit edilmiştir ${ }^{6}$. Hantavirus epidemiyolojisini irdeleyen diğer önemli bir seroprevalans çalışmasında, Giresun yöresinde insanlardan toplanan serum örneklerinde DOBV, PUUV, Saaremaa alt tiplerinin varlığı gösterilmiştir ${ }^{7}$. Ülkemizde klinik anlamda ilk hantavirus olguları 2009 yılında görülmüş; o tarihten günümüze kadar, hantaviruslar çoğunlukla olgu bildirimleri şeklinde karşımıza çıkmıştır ${ }^{8-18}$ (Tablo I). Önemli mortalite oranları nedeniyle, bu hastalardaki klinik seyir ve mortaliteyle ilişkili prediktif faktörleri bilmek, klinisyenlere ışık tutacaktır. Farklı hantavirus alt tipleriyle gelişen enfeksiyonların klinik bulguları ve prognozları Tablo II'de gösterilmiştir2,19.

\section{PATOGENEZ}

Hantavirus enfeksiyonlarının patogenezinin anlaşılması, prognozun tayini açısından oldukça önem taşımaktadır. Patogenezde virusun direkt sitopatik etkisinden ziyade, immün yanıt mekanizmalarının rol aldığı düşünülmektedir. İnhalasyonla alındıktan sonra virus, bölgesel lenf nodlarındaki ilk replikasyon sürecinin ardından, viremi yoluyla hedef organlar olan akciğer, kalp, böbrekler ve lenfoid organların vasküler endoteline yerleş-

\begin{tabular}{|lcccc|}
\hline \multicolumn{4}{|l}{ Tablo I. Ülkemizde Bugüne Kadar Yapılan Hantavirus Olgu Bildirimleri } & \\
\hline Görüldüğü il & Görüldüğü yıl & Olgu sayısı & Ölüm & Hantavirus alt tipi \\
\hline Zonguldak-Bartın $^{8}$ & 2009 & 12 & $1(\% 8)$ & PUUV \\
Giresun $^{9}$ & 2009 & 2 & 1 & DOBV \\
Sivas $^{17}$ & 2009 & 3 & 0 & DOBV, ?, ? \\
İstanbul $^{10}$ & 2010 & 1 & 1 & DOBV \\
İstanbul $^{13}$ & 2010 & 1 & 0 & DOBV \\
Kastamonu $^{11}$ & 2010 & 2 & 0 & $?$ \\
Ankara $^{12}$ & 2011 & 1 & 0 & DOBV \\
Ordu $^{14}$ & 2012 & 2 & 0 & DOBV, ? \\
Bursa $^{15}$ & 2012 & 1 & 0 & DOBV \\
İstanbul $^{16}$ & 2012 & 1 & 1 & DOBV \\
İstanbul $^{18}$ & 2013 & 2 & 0 & PUUV, DOBV \\
\hline PUUV: Puumala virus; DOBV: Dobrava virus. & & & \\
\hline
\end{tabular}


Tablo II. Farklı Hantavirus Alt Tiplerinin Oluşturduğu Hastalıklar, Klinik Bulgular ve Prognoz

\begin{tabular}{lccccc|}
\hline & Dobrava & Hantaan & Seoul & Puumala & Sin Nombre \\
\cline { 1 - 5 } $\begin{array}{l}\text { Oluşturduğu hastalık } \\
\text { Klinik bulgular (\%) }\end{array}$ & RSKA & RSKA & RSKA & RSKA & HPS \\
$\quad$ Ateş & 95 & 100 & 100 & 100 & 100 \\
Bulantı-kusma & 80 & $82-91$ & 61 & $78-83$ & 71 \\
Kas ağrısı & 65 & $91-95$ & 81 & 82 & 29 \\
Diyare, karın ağrııı & 45 & $85-92$ & 68 & $64-67$ & 24 \\
Oligüri/anüri & 45 & $60-67$ & 37 & $54-70$ & $?$ \\
Hipotansiyon & 25 & 80 & 17 & $1-2$ & 50 \\
Hematüri & 90 & 85 & 73 & $58-85$ & 57 \\
Proteinüri & 85 & 100 & 94 & $94-100$ & 40 \\
Hemodiyaliz gereksinimi (\%) & 37 & $30-40$ & 20 & $5-7$ & $?$ \\
Mortalite (\%) & 15 & $5-10$ & $<1$ & $<1$ & 40 \\
\hline RSKA: Renal sendromla seyreden kanamalı ateş, HPS: Hantavirus pulmoner sendrom. & \\
\hline
\end{tabular}

mektedir. Bundan sonra sekonder viremi ortaya çıkar ${ }^{20}$. Virusun hedef hücreye bağlanmasında $\beta 3$ integrin reseptörlerinin önemli rolü olduğu, bunların da endotel hücrelerinin yanı sıra trombosit ve makrofaj hücre membranında bulunduğu bilinmektedir ${ }^{2}$. Hedef hücrenin enfeksiyonuyla birlikte immün sistem aktivasyonu başlar ve aktive makrofajlarca tümör nekroz faktörü (TNF)- $\alpha$, interlökin (IL)-1 ve IL-6 gibi birçok sitokin salgılanır. Bu sitokinlerin etkisine bağlı olarak hipotansiyon ve şok kliniğine yol açan, vasküler geçirgenlikte artış ve damar dışına sıvı kaçışı olmaktadır.

$\mathrm{CD}^{+} \mathrm{T}$ hücreleri hantavirusla enfekte hücrelerin yıkımında rol oynamaktadır. Diğer viral enfeksiyonlara göre bu enfeksiyonlarda serum düzeyi daha yüksek olup, hastalarda serum CD4/CD8 T lenfosit oranının tersine döndüğü görülmektedir. Yüksek viremili olgularda şiddetli CD8 ${ }^{+} \mathrm{T}$ lenfosit yanıtı nedeniyle doku hasarlanması daha fazla olmakta ve bu da klinik olarak hastalığın ciddiyetine yansımaktadır ${ }^{2}$. Özellikle enfeksiyonun başlangıcında, serumda virus yükü yüksek olan hastalarda prognoz daha kötü seyretmektedir. Yapılan çalışmalarda SNV, HTNV, DOBV gibi mortalitesi yüksek alt tiplerle gelişen enfeksiyonlarda, hastalardaki virus yükünün hafif alt tiplerle seyredenlere göre daha yüksek olduğu gösterilmiştir. Ancak hastalığın patogenezinde ve prognozun tayininde diğer birçok enfeksiyonda olduğu gibi bireysel immünitenin de önemli olduğu unutulmamalıdır. Nitekim, aynı alt tip ile enfeksiyonu takiben, bazı bireyler hastalığı hafif şekilde geçirirken, bazılarında daha ciddi sonuçlar ortaya çıkmaktadır ${ }^{21}$.

RSKA olgularında renal ödem ve retroperitoneal alana sıvı kaçağı belirgin olup, ölen olguların otopsi incelemelerinde böbreklerin belirgin ödemli ve ağırığının artmış olduğu; perirenal alanlarda hemoraji, ödem, tübüllerde dejenerasyon ve iltihabi hücrelerin 
varlığı gibi bulgular saptanmaktadır. HPS olgularında akciğerlerde yaygın ödem, trakea ve plevral alanlarda mononükleer hücre infiltrasyonlarının eşlik ettiği, yaygın alveoler hasar saptanmıştır ${ }^{22}$.

\section{PROGNOZ ile íLIŞKILI FAKTÖRLER}

Hantavirus enfeksiyonlarında prognozun belirlenmesinde rol oynayan bazı faktörler aşağıda özetlenmiştir.

\section{Virusun Tipi}

Hantavirusların çeşitli alt tipleriyle gelişen enfeksiyonlarda prognoz birbirinden çok farklı olmaktadır (Tablo II). Örneğin PUUV \%1-2 gibi en düşük mortaliteyle seyrederken, DOBV için mortalite \%15'e kadar ulaşabilir. HPS'ye neden olan SNV'de ise \%40'a varan yüksek mortalite oranlarıyla karşılaşılabilmektedir ${ }^{20,23-25}$.

\section{Genetik Faktörler}

Son yıllarda genetik faktörlerin, hantavirus hastalıklarının seyrinde etkili olabileceği üzerinde durulmaktadır. Örneğin, HLA-B8, -DR3, -DQ2 alellerine sahip bireylerde hemodiyaliz ihtiyacının daha fazla ve prognozun daha kötü olduğu, HLA-B27 aleline sahip olanlarda ise hastalığın daha hafif seyir gösterdiği bildirilmiştir ${ }^{1,26}$.

\section{Demografik Özellikler}

Hantavirus enfeksiyonlarının, erkek cinsiyette daha sık görülmesine rağmen, mortalite oranlarının kadınlarda daha yüksek olduğu, Çin'de 80.671 RSKA hastası ile yapılan bir çalışmada gösterilmiş; bu durumun farklı davranışsal, sosyal ve biyolojik nedenlere bağlı olabileceği ifade edilmiştir ${ }^{27}$. Bir başka çalışmada da, yaşın mortalite ile olan ilişkisi üzerinde durulmaktadır ${ }^{28}$. İsveç'te yapılan, PUUV'nun neden olduğu 5.282 epidemik nefropati (Nefropathia epidemica; NE) hastasını içeren bir çalışmada, 50 yaş altında hastalığın akut fazı sırasında mortalite görülmediği, 80 yaş ve üzerinde ise mortalite oranının $\% 6.5$ olduğu ve ileri yaşın mortalite üzerine olumsuz etki ettiği bildirilmiştir ${ }^{28}$.

\section{Hümoral İmmün Yanıtın Yeterliliği}

Hastalığın erken döneminde, özellikle virusun nükleokapsid ( $N$ ) proteinine karşı lgM, $\operatorname{lgG}$ ve IgA tipi nötralizan antikorlar gelişmektedir. Etkin bir nötralizan antikor yanıtı, virus yayılımının sınırlandırılmasında, enfekte hücre sayısının ve dolayısıyla da sitotoksik T lenfositlerine bağlı hücre hasarının azaltılmasında oldukça önemlidir. Hantaviruslara karşı gelişen antikorlar, serumda yıllarca varlığını sürdürerek, kişiyi aynı alt tipe karşı korumaktadır ${ }^{29}$.

\section{Klinik Bulgular}

Klinik bulgular ve hastalığın şiddeti, yukarıda söz edildiği üzere, hantavirus alt tipleriyle ilişkili olarak belirgin farklılıklar göstermektedir ${ }^{1,2}$. Örneğin; SNV ve HTNV enfeksi- 
yonlarında hipotansiyon, HTNV ve SEOV enfeksiyonlarında ise peteşi daha sık görülmektedir $^{2}$. Yine HTNV ve DOBV ile olan enfeksiyonlarda, hastaların yaklaşık 1/3 kadarında hemodiyaliz gereksinimi ortaya çıkmaktadır ${ }^{2,19}$. PUUV ve DOBV enfeksiyonu sonrası, hastaların 10 yıl süreyle izlendiği bir çalışmada, takip sırasında renal fonksiyonların normal sınırlarda olduğu, ancak glomerüler filtrasyon hızındaki azalmanın DOBV ile enfekte hastalarda daha fazla görüldüğü bildirilmiştir ${ }^{30}$.

Hantavirus enfeksiyonlu hastalarda ölüm, genellikle böbrek yetmezliği, şok, kanama ve solunum yetmezliği nedeniyle olmaktadır. Klinik olarak; çoğul, santral sinir sistemi kanaması olan, sepsis tablosunda olan, disemine intravasküler koagülasyon (DIC) ve sekonder enfeksiyon gelişen olgularda mortalite riski artmaktadır. HPS sırasında, hastalarda erişkin solunum yetmezliği sendromu (Adult respiratory distress syndrome; ARDS) gelişmesi, mekanik ventilasyon desteğine gerek duyulması, dispne ve hemokonsantrasyon olması, çoklu regresyon analizlerinde, ölümle ilişkili en önemli prognostik faktörler olarak bildirilmektedir ${ }^{31,32}$.

\section{Laboratuvar Bulguları}

Hantavirus enfeksiyonlarının en önemli laboratuvar bulgularından biri trombositopeni olup, SNV enfeksiyonunda olguların hemen hepsinde saptanmaktadır ${ }^{2,19}$. Trombositopeni şiddetinin ve hastada transfüzyon gerekliliğinin mortalite ile ilişkisi gösterilmiştir $^{19,33}$. Bunun dışında hastanın ilk başvurusunda; serum beyaz küre (WBC), kan üre nitrojeni (BUN), kreatinin fosfokinaz (CPK), protrombin zamanı (PT), aktive parsiyel tromboplastin zamanı (aPTT), D-dimer ve INR (International normalized ratio) değerlerinin yüksek olması, prognostik açıdan önemli faktörler olup, mortalite riskini artırmaktadır ${ }^{9,33}$. Bu hastalarda yüksek C-reaktif protein (CRP) ve WBC değerlerinin, hastalık sürecinde tetiklenen inflamatuvar yanıta bağlı olduğu; CPK yüksekliğinin ise hem inflamatuvar süreç, hem de gelişen rabdomiyolizle ilişkili olduğu belirtilmektedir ${ }^{33}$. Kostakoğlu ve arkadaşları ${ }^{33}$, ölüm riski açısından bu parametrelerin tanısal sınır değerlerini (cut-off); WBC: $16.000 \mu^{-1}$, trombosit: $30.000 \mu \mathrm{l}^{-1}$, PT: 19.7 s, aPTT: 36 s, INR: 1.2, D-dimer: 9.3 $\mu \mathrm{g} / \mathrm{ml}$, CPK: $600 \mathrm{U} / \mathrm{L}, \mathrm{BUN}$ : $47 \mathrm{mg} / \mathrm{dl}$ ve CRP: $13.4 \mathrm{mg} / \mathrm{dl}$ olarak bildirmişlerdir. Bir viral enfeksiyon olmasına rağmen, bu olgularda CRP yüksek olup, bahsedilen sınır değeri dikkate alındığında, mortalite öngörüsü için duyarlılığın \%100, özgüllüğün \%87.5 olduğu bulunmuş; bu oranlar CPK için sırasıyla \%60 ve \%88.2 olarak saptanmıştır ${ }^{33}$.

\section{TEDAVININ PROGNOSTIK DEĞERI}

Hantavirus tedavisinde temel amaç, hastada organ ve dokularda yeterli perfüzyonun devam ettirilebilmesidir. Bu amaçla hastalarda hipotansiyon ve şoka karşı gerekli sıvı replasmanının sağlanması, oligürik-anürik olguların hemodiyaliz açısından değerlendirilmesi, hastaların kanama, solunum yetmezliği, hipotansiyon, şok, elektrolit bozuklukları bakımından yakından takip edilmeleri gereklidir. Ciddi trombositopeni varlığında trombosit replasmanı gerekli olabilmektedir ${ }^{26}$. Hemodiyaliz desteği özellikle HTNV ve DOBV 
enfeksiyonlu olgularda çok önemlidir ${ }^{2,19}$. Solunum desteği, mekanik ventilasyon uygulaması HPS olgularında yaşam kurtarıcı olabilmektedir ${ }^{34}$. HPS'de ayrıca ekstrakorporeal membran oksijenizasyonu desteğinin, hastanın sağkalımına olumlu katkı sağladığı da gösterilmiştir ${ }^{34,35}$.

Bazı hayvan ve insan çalışmalarında, ribavirinin RSKA'nın şiddetini, hemodiyaliz gereksinimini ve mortaliteyi azalttığı bildirilmekle birlikte, HPS için etkinliği gösterilmemiştir ${ }^{2,36,37}$. Çin'de yapılan 242 hastanın yer aldığı randomize, plasebo kontrollü bir çalışmada, hastalığın ilk haftasında intravenöz verilen ribavirinin, mortaliteyi yedi kat azalttığı saptanmıştır ${ }^{36}$. Kore'de yapılan, 33 RSKA hastasını içeren bir başka çalışmada, ribavirin tedavisinin, hastalarda görülen oligüri ve hemodiyaliz gereksinimi üzerine belirgin katkı sağladığı bulunmuştur ${ }^{37}$. Deneysel bir modelde, değişen dozlarda uygulanan ribavirinin, Andes virusunun tetiklediği sitokin fırtınasını kısmen baskılayabildiği, ancak tam bir süpresyon sağlayamaması nedeniyle terapotik etkinliğinin sınırlı olabileceği belirtilmiştir ${ }^{38}$. Bir başka çalışmada ise, Andes virus enfeksiyonundan korunmada, maruziyet sonrası proflaktik olarak uygulanan ribavirin başarılı bulunmuştur ${ }^{39}$. Bununla birlikte, HPS olgularında intravenöz ribavirin uygulamasının yararlı olmadığını gösteren yayınlar da mevcuttur ${ }^{2,40}$.

Şiddetli hastalığı olan hantavirus enfeksiyonlu hastalardaki serum antikor titresinin, hafif seyirli enfeksiyonu olanlara göre düşük olması, hastalıktan korunma/tedavide immünoterapiyi gündeme getirmiştir ${ }^{41}$. İnsanlarda randomize kontrollü bir çalışma olmamakla birlikte, bazı çalışmalarda hastalığın erken döneminde verilen insan nötralizan antikorlarının tedavi ve/veya proflakside etkisi olabileceği bildirilmektedir ${ }^{41}$. Korunmada aşının etkinliğine dair yapılan çalışmalar da mevcut olup, aşının aynı alt tiple reenfeksiyon gelişimini önlediği ve Andes virus enfeksiyonuna karşı koruyucu olduğu gösterilmiştir ${ }^{42,43}$.

\section{KAYNAKLAR}

1. Heyman P, Vaheri A, Lundkvist A, Avsic-Zupanc T. Hantavirus infections in Europe: from virus carriers to a major public-health problem. Expert Rev Anti Infect Ther 2009; 7(2): 205-17.

2. Jonsson CB, Figueiredo LT, Vapalahti O. A global perspective on hantavirus ecology, epidemiology, and disease. Clin Microbiol Rev 2010; 23(2): 412-41.

3. Bi Z, Formenty PB, Roth CE. Hantavirus infection: a review and global update. J Infect Dev Ctries 2008; 2(1): 3-23.

4. Pan American Health Organization. Hantavirus in the Americas: Guidelines for diagnosis, treatment, prevention, and control. Available at: http://www.paho.org/English/AD/DPC/CD/hantavirus-americas.htm

5. Klempa B. Hantaviruses and climate change. Clin Microbiol Infect 2009; 15(6): 518-23.

6. Laakkonen J, Kallio-Kokko H, Oktem MA, et al. Serological survey for viral pathogens in Turkish rodents. J Wildl Dis 2006; 42(3): 672-6.

7. Gozalan A, Kalaycıoğlu H, Uyar Y, et al. Human puumala and dobrava hantavirus infections in the Black Sea region of Turkey: a cross-sectional study. Vector Borne Zoonotic Dis 2013; 13(2): 111-8. 
8. Ertek M, Buzgan T. An outbreak caused by hantavirus in the Black Sea region of Turkey, January-May 2009. Euro Surveill 2009; 14(20). pii:19214.

9. Kaya S, Yılmaz G, Erensoy S, Yağçı Çağlayık D, Uyar Y, Köksal I. Hantavirus infection: two case reports from a province in the Eastern Black Sea Region, Turkey. Mikrobiyol Bul 2010; 44(3): 479-87.

10. Oncul O, Atalay Y, Onem Y, Turhan V, Acar A, Uyar Y. Hantavirus infection in Istanbul, Turkey. Emerg Infect Dis $2011 ; 17(2): 303-4$.

11. Öngürü $P$, Yılmaz $S, A k ı n c ı ~ E$, et al. Renal sendrom ile seyreden kanamalı ateş: İki olgu sunumu. Turk Hij Den Biyol Derg 2011; 68(1): 35-9.

12. Öncül A, Koçulu S, Çağlayık DY, Uyar Y. Giresun ilinden hafif seyirli bir hantavirus olgusu. Turk Hij Den Biyol Derg 2011; 68(4): 209-14.

13. Sarıgüzel N, Hofmann J, Canpolat AT, et al. Dobrava hantavirus infection complicated by panhypopituitarism, Istanbul, Turkey, 2010. Emerg Infect Dis 2012; 18(7): 1180-3.

14. Sünbül M, Yılmaz $H$, Çetinkaya $H$, et al. Two cases of hantavirus infection in Crimean-Congo hemorrhagic fever endemic region. J Microbiol Infect Dis 2012; 2(3): 117-20.

15. Çakır D, Çelebi S, Korukluoğlu G, Bozdemir ŞE, Çetin BŞ, Hacımustafaoğlu M. Hantavirüse bağlı renal sendromla seyreden kanamalı ateş. Ankem Derg 2012; 26(4): 198-202.

16. Atalay YO, Dere K, Şen H, Küçükodacı Z, Önem Y, Özkan S. Hantavirüs renal sendromlu hemorajik ateş: olgu sunumu ve derleme. Yoğun Bakım Derg 2012; 10(4): 210-6.

17. Gözel MG, Engin A, Elaldı N, Bakır M, Dökmetaş i, Uyar Y. First cases of hemorrhagic fever with renal syndrome from the Middle Anatolia Region of Turkey and the first case of Hantavirus and Crimean-Congo hemorrhagic fever virus co-infection in a patient. Turkiye Klinikleri J Med Sci 2013; 33(1): 224-8.

18. Özkan O, Tükek T, Yıldız E, Velioğlu EA, Gürsu M, Öztürk S. Hantavirus infections and renal manifestations: case report and update. Turk Neph Dial Transpl 2013; 22(1): 129-32.

19. Kaya S, Çağlayık DY, Uyar Y, et al. Can Hantavirus infections be predicted on admission to hospital? J Med Virol 2012; 84(11): 1790-6.

20. Bi Z, Formenty PB, Roth CE. Hantavirus infection: a review and global update. J Infect Dev Ctries 2008; 2(1): 3-23.

21. Saksida A, Duh D, Korva M, Avsic-Zupanc T. Dobrava virus RNA load in patients who have hemorrhagic fever with renal syndrome. J Infect Dis 2008; 197(5): 681-5.

22. Schönrich G, Rang A, Lütteke N, Raftery MJ, Charbonnel N, Ulrich RG. Hantavirus-induced immunity in rodent reservoirs and humans. Immunol Rev 2008; 225(1): 163-89.

23. Lednicky JA. Hantavirus: a short review. Arch Pathol Lab Med 2003; 127(1): 30-5.

24. Khan A, Khan AS. Hantaviruses: a tale of two hemispheres. Panminerva Med 2003; 45(1): 43-51.

25. Heyman P, Vaheri A, Lundkvist A, Avsic-Zupanc T. Hantavirus infections in Europe: from virus carriers to a major public-health problem. Expert Rev Anti Infect Ther 2009; 7(2): 205-17.

26. Appel GB, Mustonen J. Renal involvement with hantavirus infection (hemorrhagic fever with renal syndrome). UpToDate Inc. Available at: http://www.uptodate.com/online/content/topic.do? topicKey=renlfail /9308\&selectedTitle=2\%7E20\&source=search_result

27. Klein SL, Marks MA, Li W, et al. Sex differences in the incidence and case fatality rates from hemorrhagic fever with renal syndrome in China, 2004-2008. Clin Infect Dis 2011; 52(12): 1414-21.

28. Hjertqvist M, Klein SL, Ahlm C, Klingstrom J. Mortality rate patterns for hemorrhagic fever with renal syndrome caused by Puumala virus. Emerg Infect Dis 2010; 16(10): 1584-6.

29. Hjelle B. Pathogenesis of hantavirus infections UpToDate Inc. Available at: http://www.uptodate.com/online/content/topic.do?topicKey=viral_in/24412\&selectedTitle=4\%7E20\&source=search_result

30. Tulumovic D, Imamovic G, Mesic E, et al. Comparison of the effects of Puumala and Dobrava viruses on early and long-term renal outcomes in patients with haemorrhagic fever with renal syndrome. Nephrology (Carlton) 2010; 15(3): 340-3. 
31. da Rosa Elkhoury M, da Silva Mendes W, Waldman EA, et al. Hantavirus pulmonary syndrome: prognostic factors for death in reported cases in Brazil. Trans R Soc Trop Med Hyg 2012; 106(5): 298-302.

32. Maftei ID, Segall L, Panculescu-Gatej R, Ceianu C, Covic A. Hantavirus infection-hemorrhagic fever with renal syndrome: the first case series reported in Romania and review of the literature. Int Urol Nephrol 2012; 44(4): 1185-91.

33. Kostakoglu U, Yılmaz G, Volkan S, Sökel SK, Kaya S, Köksal I. Evaluation of clinical and laboratory predictors of fatality in patients with Hantavirus infection. J Microbiol Infect Dis 2012; 2(4): 155-9.

34. Sargianou M, Watson DC, Chra P, et al. Hantavirus infections for the clinician: from case presentation to diagnosis and treatment. Crit Rev Microbiol 2012; 38(4): 317-29.

35. Chang B, Crowley M, Campen M, Koster F. Hantavirus cardiopulmonary syndrome. Semin Respir Crit Care Med 2007; 28(2): 193-200.

36. Huggins JW, Hsiang CM, Cosgriff TM, et al. Prospective, double blind, concurrent, placebo-controlled clinical trial of intravenous ribavirin therapy of hemorrhagic fever with renal syndrome. J Infect Dis $1991 ; 164(6)$ : 1119-27.

37. Rusnak JM, Byrne WR, Chung KN, et al. Experience with intravenous ribavirin in the treatment of hemorrhagic fever with renal syndrome in Korea. Antiviral Res 2009; 81(1): 68-76.

38. Khaiboullina SF, Rizvanov AA, Lombardi VC, et al. Andes-virus-induced cytokine storm is partially suppressed by ribavirin. Antivir Ther 2013; 18(4): 575-84.

39. Safronetz D, Haddock E, Feldmann F, Ebihara H, Feldmann $\mathrm{H}$. In vitro and in vivo activity of ribavirin against Andes virus infection. PLoS One 2011; 6(8): e23560.

40. Mertz GJ, Miedzinski L, Goade D, et al; Collaborative Antiviral Study Group. Placebo-controlled, doubleblind trial of intravenous ribavirin for the treatment of hantavirus cardiopulmonary syndrome in North America. Clin Infect Dis 2004; 39(9): 1307-13.

41. Bharadwaj M, Nofchissey R, Goade D, Koster F, Hjelle B. Humoral immune responses in the hantavirus cardiopulmonary syndrome. J Infect Dis 2000; 182(1): 43-8.

42. Safronetz D, Hegde NR, Ebihara $H$, et al. Adenovirus vectors expressing hantavirus proteins protect hamsters against lethal challenge with andes virus. J Virol 2009; 83(14): 7285-95.

43. Schmaljohn C. Vaccines for hantaviruses. Vaccine 2009; 27(Suppl 4): 61-4. 